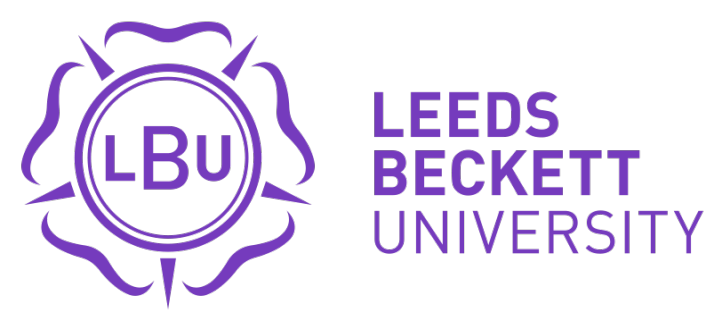

Citation:

Lloyd, R and Parr, B and Davies, S and Partridge, T and Cooke, CB (2010) A comparison of the physiological consequences of head-loading and back-loading for African and European women. European journal of applied physiology, 109 (4). 607 - 616. ISSN 1439-6319 DOI: https://doi.org/10.1007/s00421-010-1395-9

Link to Leeds Beckett Repository record:

https://eprints.leedsbeckett.ac.uk/id/eprint/326/

Document Version:

Article (Accepted Version)

The aim of the Leeds Beckett Repository is to provide open access to our research, as required by funder policies and permitted by publishers and copyright law.

The Leeds Beckett repository holds a wide range of publications, each of which has been checked for copyright and the relevant embargo period has been applied by the Research Services team.

We operate on a standard take-down policy. If you are the author or publisher of an output and you would like it removed from the repository, please contact us and we will investigate on a case-by-case basis.

Each thesis in the repository has been cleared where necessary by the author for third party copyright. If you would like a thesis to be removed from the repository or believe there is an issue with copyright, please contact us on openaccess@leedsbeckett.ac.uk and we will investigate on a case-by-case basis. 


\title{
A comparison of the physiological consequences of head-loading and back-loading for African and European women
}

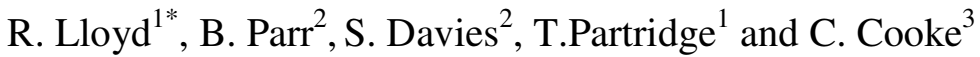

${ }^{1}$ Division of Sport and Exercise Sciences, University of Abertay Dundee, Dundee, DD1 1HG, UK

${ }^{2}$ Department of Sports Management, Cape Peninsula University of Technology

${ }^{3}$ Carnegie Research Institute, Leeds Metropolitan University, Leeds, LS6 3QS, UK

* Author for correspondence - r.lloyd@ abertay.ac.uk

Abstract: Aim: to quantify the physiological cost of head-load carriage and to examine the 'free ride' hypothesis for head-load carriage in groups of women differing in their experience of headloading. Method: Twenty four Xhosa women (13 experienced head-loaders (EXP), 11 with no experience of headloading (NON)) attempted to carry loads of up to 70\% of body mass (BM) on both their heads and backs whilst walking on a treadmill at a self selected walking speed. Expired air was collected throughout. In a second study nine women, members of the British Territorial Army (TA), carriedsimilar loads, again at a self selected speed. Results: Maximum load carried was greater for the back than the head $(54.7 \pm 15.1 \%$ v $40.8 \pm 13.2 \%$ BM, $\mathrm{P}<0.0005)$. Considering study one, head-loading required a greater oxygen rate than back-loading $(10.1 \pm 2.6$ ml.kgbodymass ${ }^{-1} \cdot \mathrm{min}^{-1} \mathrm{v} 8.8 \pm 2.3$ ml.kgbodymass ${ }^{-1} \cdot \mathrm{min}^{-1}, \mathrm{P}=0.043$, for loads $10-25 \% \mathrm{BM}$ ) regardless of previous head-loading experience $(\mathrm{P}=0.333)$. Percentage changes in oxygen consumption associated with head-loading were greater than the proportional load added in both studies but were smaller than the added load for the lighter loads carried on the back in study 1 . Allother physiological variables were consistent with changes in oxygen consumption.

Conclusion: The data provides no support for the 'free ride' hypothesis for head-loading although there is some evidence of energy saving mechanisms for back-loading at low speed/load combinations. Investigating the large individual variation in response may help in identifying combinations of factors that contribute to improved economy. 


\section{Introduction}

The necessity to transport relatively heavy loads remains an important occupational task for many people, including school students and the military. Consequently much attention has been paid to load carriage with a number of different approaches evident in the literature. The analytical perspectives employed include: kinematics (e.g. Sharpe et al, 2008; LaFiandra et al, 2003), kinetics (e.g. Chow et al, 2005; Birrell et al, 2007), electromyography (e.g.AlKhabbaz et al, 2008; Bobet and Norman, 1984) and subjective perceptual responses (e.g. Birrell and Hooper, 2007; Mackie and Legg, 2008). By far the most prevalent approach, however, has been an examination of the physiological consequences of carrying loads (e.g. Bastien et al, 2005a; Abe et al, 2004). For the most part these analyses have considered the energetic consequences of load carriage through an examination of oxygen consumption.

One particular area that has been explored in some detail is that of the effect of load placement and load carrying method on energy expenditure. Taylor et al (1980) demonstrated, across a range of species, that, for loads carried on the back, the increase in energy expenditure associated with a given load was directly proportional to the relative increase in mass i.e. an additional load of $10 \%$ body mass evokes a $10 \%$ increase in energy expenditure. This result has been replicated in numerous human studies (e.g.Quesda et al, 2000; Rorke, 1990). Studies examining the effect of load placement on energy expenditure have generally shown significant advantages for load placements close to the trunk as opposed to loads carried more distally, in the hands or on the feet (e.g. Soule and Goldman 
1969). There are, however, either only small or no advantages for particular loading methods when the methods compared all involve loading of the trunk (e.g. Kirk and Schneider, 1992; Holewijn, 1990). Datta and Ramanathan (1971) and Legg and Mahanty (1985) both compared a range of loading conditions and found small advantages for double pack systems, where the load was carried split between the back and the front of the trunk, over back-loading alone. These findings were supported by Lloyd and Cooke (2000a). Stuempfle et al (2004) reported a significant advantage for loads carried high on the back compared to loads carried in a low position. Similarly, Obusek et al (1997) examined the effect of the location of the centre of mass of a backpack on energy cost. They found a significant linear relationship between the position of the centre of mass and energy cost with positions close to the body and high on the back being associated with lower metabolic cost.

In the developing world heavy loads are regularly carried over long distances as a necessary part of daily routine. Most commonly the method employed is some form of head-loading, either with the load carried on the back but supported by a forehead strap (e.g. Nepalese porters) or directly on the head (e.g. African women). It has been argued that both of these methods represent particularly economical solutions to the problem of carrying loads in these environments (Maloiy et al, 1986; Charteris et al (1989 a,b);Bastien et al, 2005b). The head strap method has received some recent attention. Minetti et al (2006) concluded that the remarkable capabilities of the Himalayan porters could only partially be explained by metabolic efficiency whilst Malville et al (2001) argued that a combination of pacing strategy and metabolic efficiency contribute to the load carrying abilities of the commercial porters in Eastern Nepal. Both studies seem 
to support the early findings of Nag et al (1979) who reported this method as being particularly economical when heavy loads are carried at relatively slow speeds.

The data for direct head-loading are more inconsistent. Maloiy et al (1986) reported a phenomenon whereby African women could carry loads of up to $20 \%$ body mass with no additional energy expenditure, with a linear relationship thereafter (i.e. loads of $30 \%$ body mass required a $10 \%$ increase in energy expenditure). This ability to carry loads of up to $20 \%$ body mass with no additional energy expenditure above that required for unloaded walking has become known as the 'free ride' hypothesis (Charteris et al, 1989). The findings of Maloiy et al (1986) were particularly interesting as they suggested that both direct head-loading and the forehead strap method were exceptionally economical regardless of the method employed. The study involved a total of five women from two different ethnic groups, each of which employed a different headloading method. The Luo women $(n=3)$ carried the loads directly on their heads whilst the Kikuyu women $(n=2)$ carry the loads on their backs, supported by a head strap. Charteris et al (1989) provide support for the 'free ride hypothesis' based on a study involving six Xhosa women who were direct head-loaders. Jones et al (1987) suggested that the existence of a 'free ride' was predicated on the relative contribution of body fat to the overall load. Of the eight Mandinka women they assessed, all employing the direct head-loading method, four appeared to follow the patterns indicated by Maloiy et al (1986) whilst the remainder demonstrated the more typical proportional response. The defining characteristic of the two groups was body composition and Jones et al (1987) concluded that African women could be extremely economical load carriers only 
if they were lean. They suggested that any external load and body fat combination up to $140 \%$ fat free mass could be carried, directly on the head, with no additional energy expenditure.

In contrast to Maloiy et al (1986), Jones et al (1987) and Charteris et al (1989), the earlier studies of Soule and Goldman (1969), Datta and Ramanathan (1971) and Datta et al (1973) all suggest that the energy cost of direct head-loading is broadly in line with the proportional increase associated with back-loading. Thus, it is striking that there has been no systematic investigation into the generalisability of the free-ride hypothesis. Rather the subsequent literature has sought to biomechanically explain the phenomenon and has been based around reinterpretation and analysis of the physiological data from Maloiy (1986) (e.g. Heglund et al, 1995). No contemporary physiological data exists for head-loading in African women. The purpose of this study was, therefore, to provide a more comprehensive description of the physiological consequences of head-loading for both experienced and not experienced participants than currently exists in the literature and, via comparison with back-loading, provide a more systematic investigation of the 'free ride' hypothesis.

\section{Methods}

\subsection{Participants}

Twenty four Xhosa women, thirteen with at least ten years experience of head load carriage (EXP) and eleven with no experience of head load carriage (NON) 
were recruited to take part in study 1, whilst nine British women, all members of the Territorial Army with no experience of head load carriage but significant experience of back-loading, took part in study 2 (TA). All participants gave informed consent for their participation in the studies. Both studies had received ethical approval through standard institutional review procedures at both the University of Abertay Dundee and Cape Peninsula University of Technology.

The women in all three groups were of similar age $(22.5 \pm 2.1,21.2 \pm 2.4$ and $21.8 \pm 1.8$ years for EXP, NON and TA respectively, $\mathrm{P}=0.765$ ) and body mass $(66.0 \pm 12.8,66.8 \pm 14.5$ and $67.4 \pm 8.4 \mathrm{~kg}$ for EXP, NON and TA respectively, $\mathrm{P}=0.967$ ). The TA group were, however, significantly taller than either the EXP or NON groups $(165 \pm 5.4 \mathrm{~cm} \mathrm{v} 159 \pm 5.1 \mathrm{~cm}$ and $158 \pm 5.3 \mathrm{~cm}$ respectively, $\mathrm{P}=0.011)$

\subsection{Study 1}

\subsubsection{Experimental Procedures}

The women each attended the Human Performance Laboratory at Cape Peninsula University of Technology on three separate occasions. On the first occasion participants were screened for any potential contraindications to exercise, stature and mass were assessed, and questionnaires were completed relating to load carriage history. The women were then habituated to the experimental protocol and the equipment to be used. A typical habituation session lasted between twenty and thirty minutes and involved the women walking on the treadmill at 
various speeds both with and without a face mask. In addition they also tried out the two load carrying devices, a standard 451 backpack (Karrimor, SA) for back loading and a plastic crate for head loading (the crate placed either directly on the head or on a small piece of rolled cloth to provide some cushioning), with and without loads. At the end of the session the women were asked to walk on the treadmill at a speed that they felt would be comfortable when carrying a heavy load. The chosen walking speed of each participant was noted and used for the subsequent experimental trials.

On arrival at the laboratory at the next visit each participant chose at random, via the picking of a piece of paper (marked with either ' $\mathrm{H}$ ' or ' $\mathrm{B}$ ') from a hat, the loading method for the first experimental trial. This involved walking, at the previously determined speed, for four minutes unloaded and then, after a one minute rest, a load of $10 \%$ body mass was added. This load was then carried for a further four minutes. After a further rest of one minute the load was increased to $15 \%$ and carried for four minutes. This pattern was repeated with loads of $20 \%$, $25 \%, 30 \%, 40 \%, 50 \%, 60 \%$ and $70 \%$ of body mass or until pain and discomfort led to voluntary cessation of the session. Workloads of four minutes duration were employed based on pilot work which showed that steady state oxygen consumption was achieved within this time. This is consistent with previous studies in the area (e.g. Lloyd et al 2000a) The load was calculated based on the body mass at the habituation session and was made up of the mass of the actual carrying device plus appropriate weightlifting plates, (between $2.5 \mathrm{~kg}$ and $10 \mathrm{~kg}$ ), and $100 \mathrm{~g}$ sandbags, which allowed the load to be adjusted to within $50 \mathrm{~g}$ of the required load. Each participant attended the laboratory one week later to repeat the experiment with the other loading device. 


\subsubsection{Data collection and analysis}

All participants were fitted with a face mask and expired air was collected throughout the protocol by means of an on-line gas analysis system (Quark b2, Cosmed, Rome). The system was calibrated prior to each test in accordance with manufacturer's instructions using gases of known concentration $\left(16 \% \mathrm{O}_{2}, 4 \%\right.$ $\mathrm{CO}_{2)}$ and room air. Participants were also fitted with a heart rate monitor (Polar, Finland). All measured cardiorespiratory variables (oxygen consumption, minute ventilation, carbon dioxide production, breathing frequency, tidal volume and heart rate) were subsequently averaged over the final minute of each workload. These were then analysed using an ANOVA with repeated measures (SPSS, v16.0). All multiple comparisons were accomplished after use of a Bonferroni correction. Percentage changes over unloaded walking were calculated for key variables and compared via a repeated measures group x method ANOVA. In study 1 all women carried at least $25 \%$ BM in both conditions whilst in study 2 all women carried at least $30 \% \mathrm{BM}$ in both conditions. The analysis will reflect this with, for study 1 data, method x group x load ANOVAs for 0-25\% BM and method x load ANOVAs for loads of $0-30 \%$ BM for study 2 . For study 1 a further method $\mathrm{x}$ group ANOVA will be used to analyse data at $30 \% \mathrm{BM}(\mathrm{n}=10$ for both NON and EXP) and a simple ANOVA comparing method will be performed to analyse data at 40\% BM ( $\mathrm{n}=12,8 \mathrm{EXP}, 4 \mathrm{NON})$ and 50\% BM (n=7, 5 EXP, 2 NON.)

Maximum load carried was recorded and compared between the groups and 
conditions by means of a further ANOVA with repeated measures. Univariate ANOVA was used to assess differences in physical characteristics and walking speed between the three groups.

\subsection{Study 2}

The second study took place at the Human Performance Laboratory of the University of Abertay Dundee and differed from study 1 only in respect of: the loads to be carried $(0,10 \%, 20 \%, 30 \%, 40 \%, 50 \% 60 \%$ and $70 \% \mathrm{BM})$, the online gas analysis system which was a Metalyzer $3 b$ (Cortex, Germany), the backpack used was a standard British Army issue Bergen and the walking speed was $4.33 \pm$ $0.19 \mathrm{~km}^{-1}$, significantly faster than either the EXP or the NON groups in study 1 $(\mathrm{P}<0.0005)$.

\section{Results}

\subsection{Chosen walking speed}

The walking speeds chosen by the women in study 1 were not significantly different $\left(3.15 \pm 0.45\right.$ and $3.00 \pm 0.30 \mathrm{~km}^{-1}$ for EXP and NON respectively, $\mathrm{P}=0.607)$. These speeds were, however, significantly slower than the walking speed chosen by the TA women $\left(4.33 \pm 0.19 \mathrm{~km}^{-1}, \mathrm{P}<0.0005\right)$

\subsection{Load carried}


Considering study 1, significantly greater load was carried on the back than on the head $(\mathrm{P}=0.014)$, with the average maximum load associated with head-carriage being $41.5 \pm 14.4 \% \mathrm{BM}$ versus $51.5 \pm 15.8 \% \mathrm{BM}$ for back load carriage. These equate to absolute loads of $26.8 \pm 8.6 \mathrm{~kg}$ and $33.2 \pm 9.4 \mathrm{~kg}$ respectively. There was no significant difference between the groups overall $(\mathrm{P}=0.308)$ and the response was consistent between the two groups $(\mathrm{P}=0.845)$ with mean differences were $5.9 \mathrm{~kg}$ and $6.8 \mathrm{~kg}$ for the EXP and NON groups respectively. Two of the EXP group and four of the NON group carried more on their head than on their back, five EXP carried the same in both conditions whilst six EXP and seven NON carried more on their backs than on their heads. Considering the TA group the load carried on the back, $63.3 \pm 8.7 \% \mathrm{BM}$, was significantly greater than the load carried on the head $(\mathrm{P}=.001), 38.9 \pm 9.3 \% \mathrm{BM}$. These equate to absolute loads of $43.1 \pm 10.0 \mathrm{~kg}$ and $25.9 \pm 5.3 \mathrm{~kg}$ respectively. One of the TA group carried the same load in both conditions whilst the rest carried more on their backs.

\subsection{Oxygen Consumption}

Considering study 1 , unloaded oxygen consumption $\left(\mathrm{ml}^{\mathrm{kg}} \mathrm{kg}^{-1} \cdot \mathrm{min}^{-1}\right)$ was not different between the successive measurements in each of the two conditions ( 8.3 $\pm 2.1 \mathrm{ml} \cdot \mathrm{kg}^{-1} \cdot \mathrm{min}^{-1} \mathrm{v} 7.7 \pm 1.8 \mathrm{ml} \cdot \mathrm{kg}^{-1} \cdot \mathrm{min}^{-1}$ for head- and back-loading respectively, $\mathrm{P}=0.261$ ). Considering all loads $10-25 \% \mathrm{BM}$ oxygen consumption was greater than the unloaded condition $(\mathrm{P}<0.0005)$ and, moreover, the average oxygen consumption across all loads associated with head-loading was significantly greater than that associated with back-loading $\left(10.1 \pm 2.6 \mathrm{ml} . \mathrm{kg}^{-}\right.$ ${ }^{1} \cdot \mathrm{min}^{-1}$ v $8.8 \pm 2.3 \mathrm{ml} \cdot \mathrm{kg}^{-1} \cdot \mathrm{min}^{-1}$ respectively, $\mathrm{P}=0.043$ ). The pattern of response between the groups was consistent (method $\mathrm{x}$ group interaction, $\mathrm{P}=0.333$, figure 1 
and table 1) as was the pattern across increasing loads (method $\mathrm{x}$ load interaction $\mathrm{P}=0.120$ ). There was also a significantly greater oxygen consumption associated with the head loading condition at the $30 \% \mathrm{BM}$ load $\left(11.4 \pm 3.3 \mathrm{ml} \cdot \mathrm{kg}^{-1} \cdot \mathrm{min}^{-1} \mathrm{v}\right.$ $9.6 \pm 2.9 \mathrm{ml} \cdot \mathrm{kg}^{-1} \cdot \mathrm{min}^{-1}$ for head- and back-loading respectively, $\mathrm{P}=0.041, \mathrm{n}=15$ ) but not at either $40 \% \mathrm{BM}\left(11.6 \pm 3.1 \mathrm{ml} \cdot \mathrm{kg}^{-1} \cdot \mathrm{min}^{-1} \mathrm{v} 10.4 \pm 3.6 \mathrm{ml} \cdot \mathrm{kg}^{-1} \cdot \mathrm{min}^{-1}, \mathrm{P}=\right.$ $0.249, \mathrm{n}=11)$ or $50 \% \mathrm{BM}\left(12.2 \pm 2.9 \mathrm{ml} \cdot \mathrm{kg}^{-1} \cdot \mathrm{min}^{-1} \mathrm{v} 11.3 \pm 4.2 \mathrm{ml} \cdot \mathrm{kg}^{-1} \cdot \mathrm{min}^{-1}, \mathrm{P}=\right.$ 0.247, $\mathrm{n}=7$ ). Again the pattern of response was consistent across the groups with group by method interactions of $\mathrm{P}=0.780$ at $30 \% \mathrm{BM}$ and $\mathrm{P}=0.280$ at $40 \% \mathrm{BM}$.

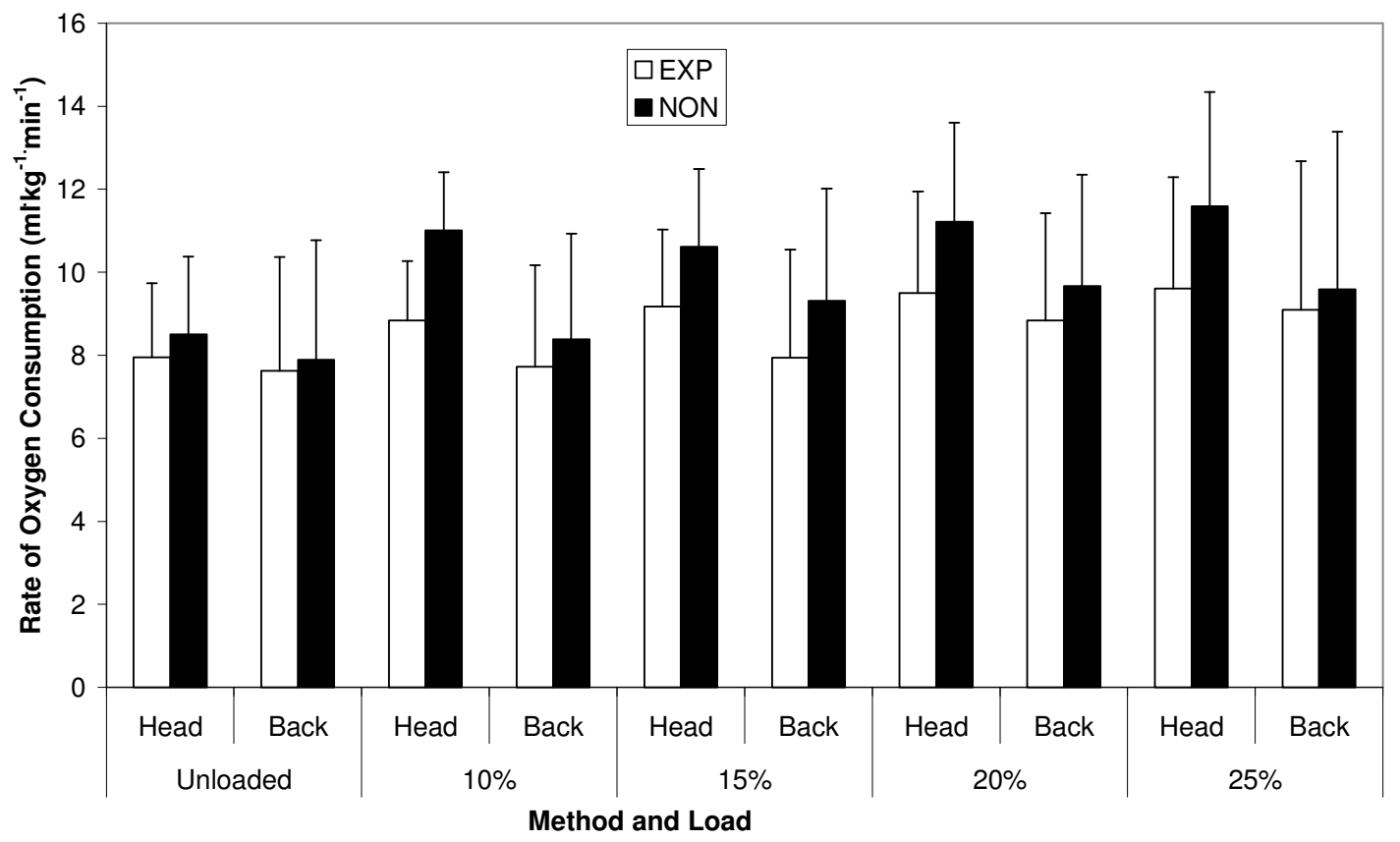

Fig 1 Mean (+s) Oxygen Consumption $\left(\mathrm{ml}^{\mathrm{kg}} \mathrm{kg}^{-1} \cdot \mathrm{min}^{-1}\right)$ for each group at loads of 10-25\% BM in each condition for study 1

Considering study 2 , unloaded oxygen consumption $\left(\mathrm{ml}^{\mathrm{kg}} \mathrm{kg}^{-1} \cdot \mathrm{min}^{-1}\right)$ was not different between the two successive measurements in each of the two conditions $\left(11.6 \pm 1.4 \mathrm{ml} \cdot \mathrm{kg}^{-1} \cdot \mathrm{min}^{-1} \mathrm{v} 11.3 \pm 1.3 \mathrm{ml} \cdot \mathrm{kg}^{-1} \cdot \mathrm{min}^{-1}\right.$ for head- and back-loading 
respectively, $\mathrm{P}=0.598$ ). Oxygen consumptions associated with all loads were greater than the unloaded condition $(\mathrm{P}<0.0005)$. Considering all loads $10-30 \%$ $\mathrm{BM}$, there was no difference in oxygen consumption associated with the head and back conditions $\left(15.2 \pm 2.6 \mathrm{ml} \cdot \mathrm{kg}^{-1} \cdot \mathrm{min}^{-1} \mathrm{v} 14.2 \pm 2.1 \mathrm{ml} \cdot \mathrm{kg}^{-1} \cdot \mathrm{min}^{-1}\right.$ respectively, $\mathrm{P}=0.081)$. Responses were consistent with increasing load $(\mathrm{P}=0.706$ for the method $\mathrm{x}$ load interaction, figure 2 and table 1).

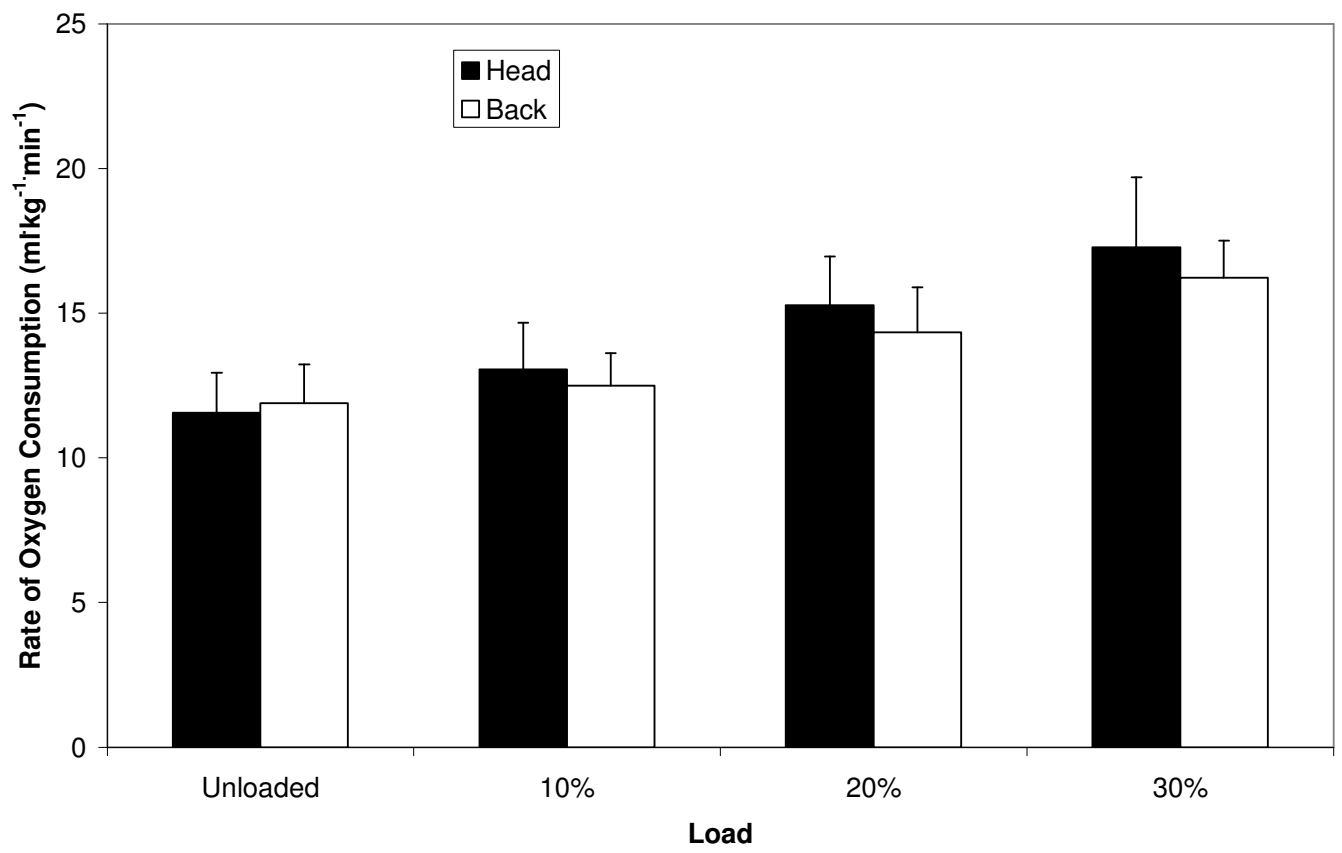

Fig 2 Mean (+s) Oxygen Consumption $\left(\mathrm{ml} \cdot \mathrm{kg}^{-1} \cdot \mathrm{min}^{-1}\right)$ at loads of $10-30 \%$ BM in each condition for study 2

Figure 3 shows the percentage difference in oxygen consumption above the unloaded condition in each condition for both studies. In the case of study 1 , and in the light of the lack of group interaction effects data is calculated for EXP and NON combined. The line $y=x$ is added to aid comparison between each condition and a directly proportionate response. 


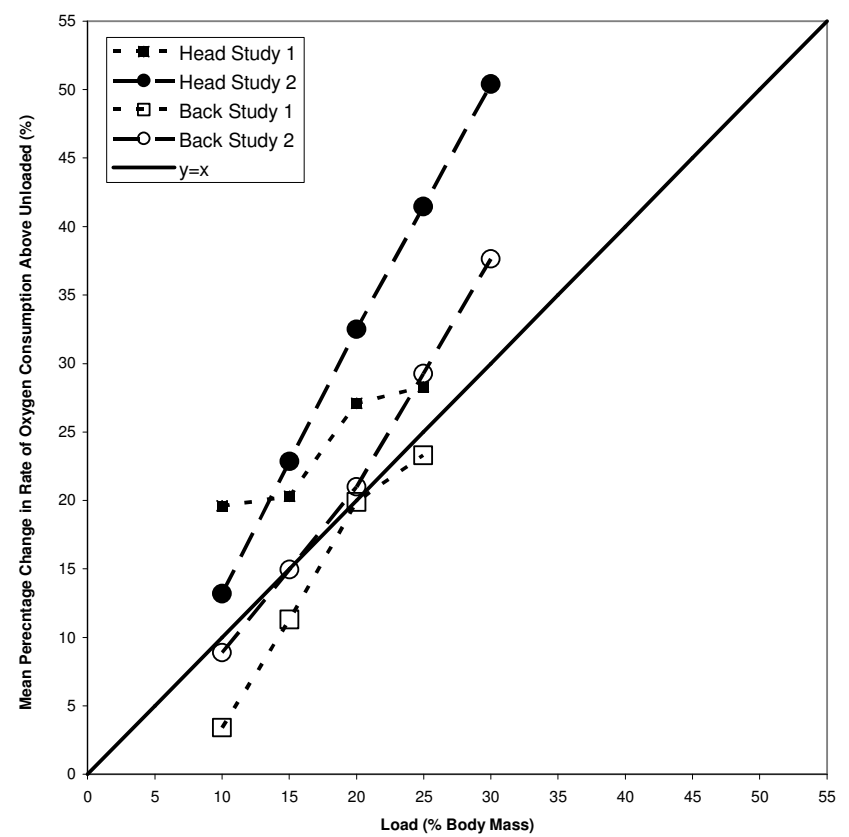

Fig 3 Mean percentage difference in oxygen consumption in each of the loading conditions for all participants in both study 1 and study 2

\subsection{Other Cardiorespiratory variables}

The lack of interaction effects involving group for study 1 (EXP and NON) was consistent across the rest of the variables measured. Consequently Table 1 contains combined data for both groups in study 1 . The data in table 1 suggest that the pattern of response for all other variables measured is similar to that for the oxygen consumption data. This is summarized in figure 4 which shows a summary of percentage differences, calculated as increase above back-load condition for head-loading, presenting mean values across 10-25\% BM loads for study 1 and $10-30 \%$ BM loads for study 2 , for each variable.

Table 1. Mean $\pm \mathrm{s}$ for participants in study 1 and study 2 at each load for all variables. Data for $30 \% \mathrm{BM}$ represents 20 participants for study 1 (10 EXP and $10 \mathrm{NON})$. * and bold indicates significant difference $(\mathrm{P}<0.05)$ between loading conditions whilst ' $\mathrm{b}$ ' indicates a trend for difference $(0.05<\mathrm{P}<0.10)$ between loading conditions. 


\begin{tabular}{|c|c|c|c|c|c|c|c|c|c|c|c|}
\hline & & \multicolumn{2}{|c|}{$10 \% \mathrm{BM}$} & \multicolumn{2}{|c|}{$15 \% \mathrm{BM}$} & \multicolumn{2}{|c|}{$20 \% \mathrm{BM}$} & \multicolumn{2}{|c|}{$25 \% \mathrm{BM}$} & \multicolumn{2}{|c|}{$30 \% \mathrm{BM}$} \\
\hline & & Head & Back & Head & Back & Head & Back & Head & Back & Head & Back \\
\hline \multirow{4}{*}{$\begin{array}{l}\dot{V O}_{2} \\
\left(\mathrm{ml} \cdot \mathrm{kg}^{-1} \cdot \mathrm{min}^{-1}\right)\end{array}$} & $\overline{\text { All }}$ & $9.8 \pm 2.6^{*}$ & $8.0 \pm 2.2^{*}$ & $9.8 \pm 2.4^{b}$ & $8.6 \pm 2.1^{b}$ & $10.3 \pm 2.4$ & $9.2 \pm 2.3$ & $10.5 \pm 3.0^{b}$ & $9.3 \pm 2.3^{b}$ & $11.5 \pm 3.3^{*}$ & $9.6 \pm 2.9 *$ \\
\hline & EXP & $8.8 \pm 1.8^{c}$ & $7.7 \pm 2.7^{\mathrm{c}}$ & $9.2 \pm 1.4^{\mathrm{c}}$ & $7.9 \pm 2.4^{\mathrm{c}}$ & $9.5 \pm 19^{c}$ & $8.8 \pm 2.6^{c}$ & $9.6 \pm 2.4$ & $9.1 \pm 2.6$ & $10.8 \pm 2.7$ & $9.2 \pm 3.6$ \\
\hline & NON & $11.0 \pm 1.8^{\mathrm{c}}$ & $8.4 \pm 2.9^{c}$ & $10.6 \pm 1.4^{c}$ & $9.3 \pm 2.5^{c}$ & $11.2 \pm 1.9^{c}$ & $9.7 \pm 2.7^{\mathrm{c}}$ & $11.6 \pm 2.4$ & $9.6 \pm 2.7$ & $12.0 \pm 2.8$ & $9.9 \pm 3.8$ \\
\hline & TA & $13.1 \pm 1.3$ & $12.5 \pm 1.1$ & & & $15.3 \pm 1.7$ & $14.3 \pm 1.6$ & & & $17.3 \pm 2.4$ & $16.2 \pm 1.3$ \\
\hline \multirow{4}{*}{$\begin{array}{l}\dot{V} e \\
\left(1 \min ^{-1}\right)\end{array}$} & 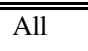 & $2021.0 \pm 5.6^{*}$ & $17.9 \pm 4.8^{*}$ & $20.4 \pm 5.3^{*}$ & 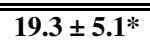 & $22.2 \pm 5.8^{*}$ & $20.3 \pm 5.0^{*}$ & $23.1 \pm 6.5^{\mathrm{b}}$ & $21.4 \pm 5.6^{\mathrm{b}}$ & $23.5 \pm 6.7 *$ & $20.8 \pm 5.3^{*}$ \\
\hline & EXP & $18.2 \pm 4.1$ & $17.3 \pm 6.0$ & $19.3 \pm 4.0$ & $18.5 \pm 5.9$ & $19.7 \pm 5.5$ & $19.9 \pm 5.4$ & $20.6 \pm 6.3$ & $20.6 \pm 6.2$ & $21.0 \pm 5.8$ & $20.2 \pm 6.6$ \\
\hline & NON & $24.4 \pm 5.0^{*}$ & $18.7 \pm 6.4^{*}$ & $23.7 \pm 4.1^{b}$ & $20.2 \pm 6.2^{b}$ & $25.2 \pm 5.2 *$ & $20.7 \pm 5.7 *$ & $26.0 \pm 6.5^{\mathrm{b}}$ & $22.4 \pm 6.4^{\mathrm{b}}$ & $25.9 \pm 5.9$ & $21.5 \pm 6.7$ \\
\hline & TA & $23.1 \pm 4.4$ & $22.3 \pm 4.6$ & & & $26.7 \pm 4.8^{*}$ & $22.5 \pm 4.1^{*}$ & & & $29.6 \pm 8.1$ & $25.7 \pm 4.6$ \\
\hline \multirow{4}{*}{$\begin{array}{l}\dot{V} \mathrm{Co}_{2} \\
\left(\mathrm{ml}^{2} \mathrm{~min}^{-1}\right)\end{array}$} & AAll & $\overline{c 538 \pm 182 *}$ & 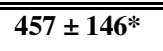 & $541 \pm 179 *$ & $490 \pm 156^{*}$ & $2566 \pm 187$ & $530 \pm 171$ & $\bar{c} 593 \pm 203^{b}$ & $\bar{c} 539 \pm 182^{b}$ & $610 \pm 218^{*}$ & $523 \pm 167^{*}$ \\
\hline & EXP & $450 \pm 149^{a}$ & $432 \pm 192^{a}$ & $473 \pm 132^{c}$ & $458 \pm 184^{c}$ & $484 \pm 164$ & $512 \pm 194$ & $515 \pm 191$ & $523 \pm 215$ & $536 \pm 200$ & $501 \pm 208$ \\
\hline & NON & $643 \pm 150^{a}$ & $487 \pm 202^{a}$ & $621 \pm 138^{c}$ & $529 \pm 194^{c}$ & $664 \pm 171$ & $550 \pm 204$ & $685 \pm 200$ & $558 \pm 226$ & $684 \pm 211$ & $546 \pm 220$ \\
\hline & TA & $734 \pm 84$ & $665 \pm 123$ & & & $855 \pm 96^{*}$ & $681 \pm 80^{*}$ & & & $963 \pm 226^{*}$ & $799 \pm 73^{*}$ \\
\hline \multirow{4}{*}{$\begin{array}{l}\text { TV } \\
(\mathrm{ml})\end{array}$} & All & $763 \pm 217^{*}$ & 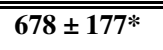 & $743 \pm 182$ & $688 \pm 176$ & $759 \pm 189$ & $710 \pm 186$ & 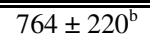 & 70705 v $206^{b}$ & $\bar{l} 765 \pm 211^{b}$ & $\bar{c} 690 \pm 213^{b}$ \\
\hline & EXP & $661 \pm 216^{a}$ & $639 \pm 228^{a}$ & $671 \pm 168^{a}$ & $644 \pm 214^{a}$ & $674 \pm 197^{a}$ & $660 \pm 226^{a}$ & $671 \pm 237^{a}$ & $652 \pm 252^{a}$ & $676 \pm 208$ & $652 \pm 261$ \\
\hline & NON & $884 \pm 218^{a, c}$ & $724 \pm 234^{a, c}$ & $827 \pm 160^{a}$ & $739 \pm 217^{a}$ & $858 \pm 198^{a}$ & $769 \pm 223^{a}$ & $874 \pm 230^{a}$ & $767 \pm 247^{a}$ & $854 \pm 217$ & $728 \pm 267$ \\
\hline & TA & $971 \pm 228$ & $882 \pm 131$ & & & $1011 \pm 146$ & $841 \pm 81$ & & & $1054 \pm 248$ & $918 \pm 56$ \\
\hline \multirow{4}{*}{$\begin{array}{l}\mathrm{BF} \\
\left(\text { breaths } \min ^{-1} \text { ) }\right.\end{array}$} & "All & $28.2 \pm 6.1^{*}$ & $20.7 \pm 4.7 *$ & $29.2 \pm 5.4$ & $2828.3 \pm 4.9$ & $29.8 \pm 6.5$ & $29.2 \pm 5.7$ & $31.0 \pm 7.0$ & $31.5 \pm 7.6$ & $3131.2 \pm 6.3$ & $3131.3 \pm 7.5$ \\
\hline & EXP & $27.8 \pm 7.9$ & $27.2 \pm 6.0$ & $28.9 \pm 6.9$ & $28.9 \pm 5.7$ & $29.3 \pm 8.6$ & $30.3 \pm 7.0$ & $30.8 \pm 9.1$ & $32.0 \pm 9.9$ & $31.0 \pm 7.8$ & $31.8 \pm 9.7$ \\
\hline & NON & $28.7 \pm 6.4$ & $26.2 \pm 5.6$ & $29.6 \pm 5.8$ & $27.6 \pm 5.5$ & $30.5 \pm 6.8^{*}$ & $27.8 \pm 5.3^{*}$ & $31.1 \pm 7.3$ & $30.8 \pm 6.8$ & $31.5 \pm 6.8$ & $30.8 \pm 7.1$ \\
\hline & TA & $25.9 \pm 7.1$ & $26.6 \pm 3.3$ & & & $27.8 \pm 5.1$ & $27.9 \pm 4.3$ & & & $29.4 \pm 7.5$ & $29.0 \pm 5.7$ \\
\hline \multirow{4}{*}{$\begin{array}{l}\mathrm{HR} \\
\left(\text { beats } \min ^{-1}\right)\end{array}$} & $\begin{array}{c}\text { All } \\
\end{array}$ & $10108 \pm 12^{*}$ & $10101 \pm 11 *$ & $1111 \pm 12 *$ & $10104 \pm 11 *$ & $10112 \pm 13^{*}$ & 106 v 12* & $1115 \pm 14 *$ & $10110 \pm 13^{*}$ & $1719 \pm 13 *$ & $10111 \pm 13 *$ \\
\hline & EXP & $107 \pm 11$ & $101 \pm 13$ & $109 \pm 12$ & $105 \pm 14$ & $109 \pm 14$ & $106 \pm 15$ & $112 \pm 15$ & $110 \pm 15$ & $118 \pm 13$ & $112 \pm 15$ \\
\hline & NON & $111 \pm 12$ & $101 \pm 13$ & $113 \pm 13^{b}$ & $103 \pm 14^{\mathrm{b}}$ & $116 \pm 15^{*}$ & $107 \pm 15^{*}$ & $119 \pm 16$ & $110 \pm 16$ & $120 \pm 13$ & $111 \pm 15$ \\
\hline & $\mathrm{TA}$ & $114 \pm 17^{*}$ & $96 \pm 15^{*}$ & & & $120 \pm 18 *$ & $104 \pm 16^{*}$ & & & $127 \pm 25^{*}$ & $114 \pm 16^{*}$ \\
\hline \multirow{4}{*}{ RER } & "All & 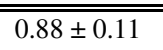 & 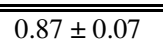 & " $0.88 \pm 0.12$ & 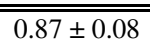 & $0.88 \pm 0.09$ & 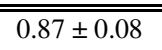 & 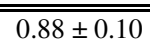 & 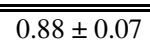 & 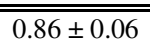 & $0.86 \pm 0.08$ \\
\hline & EXP & $0.87 \pm 0.09$ & $0.87 \pm 0.09$ & $0.87 \pm 0.08$ & $0.89 \pm 0.09$ & $0.87 \pm 0.08$ & $0.89 \pm 0.09$ & $0.87 \pm 0.09$ & $0.89 \pm 0.09$ & $0.84 \pm 0.06$ & $0.88 \pm 0.10$ \\
\hline & $\mathrm{NON}$ & $0.89 \pm 0.10$ & $0.86 \pm 0.09$ & $0.89 \pm 0.08$ & $0.85 \pm 0.10$ & $0.90 \pm 0.07^{b}$ & $0.85 \pm 0.09^{b}$ & $0.90 \pm 0.10$ & $0.87 \pm 0.09$ & $0.89 \pm 0.06$ & $0.84 \pm 0.10$ \\
\hline & TA & $0.83 \pm 0.04$ & $0.83 \pm 0.08$ & & & $0.84 \pm 0.04$ & $0.84 \pm 0.07$ & & & $0.84 \pm 0.06$ & $0.85 \pm 0.05$ \\
\hline
\end{tabular}




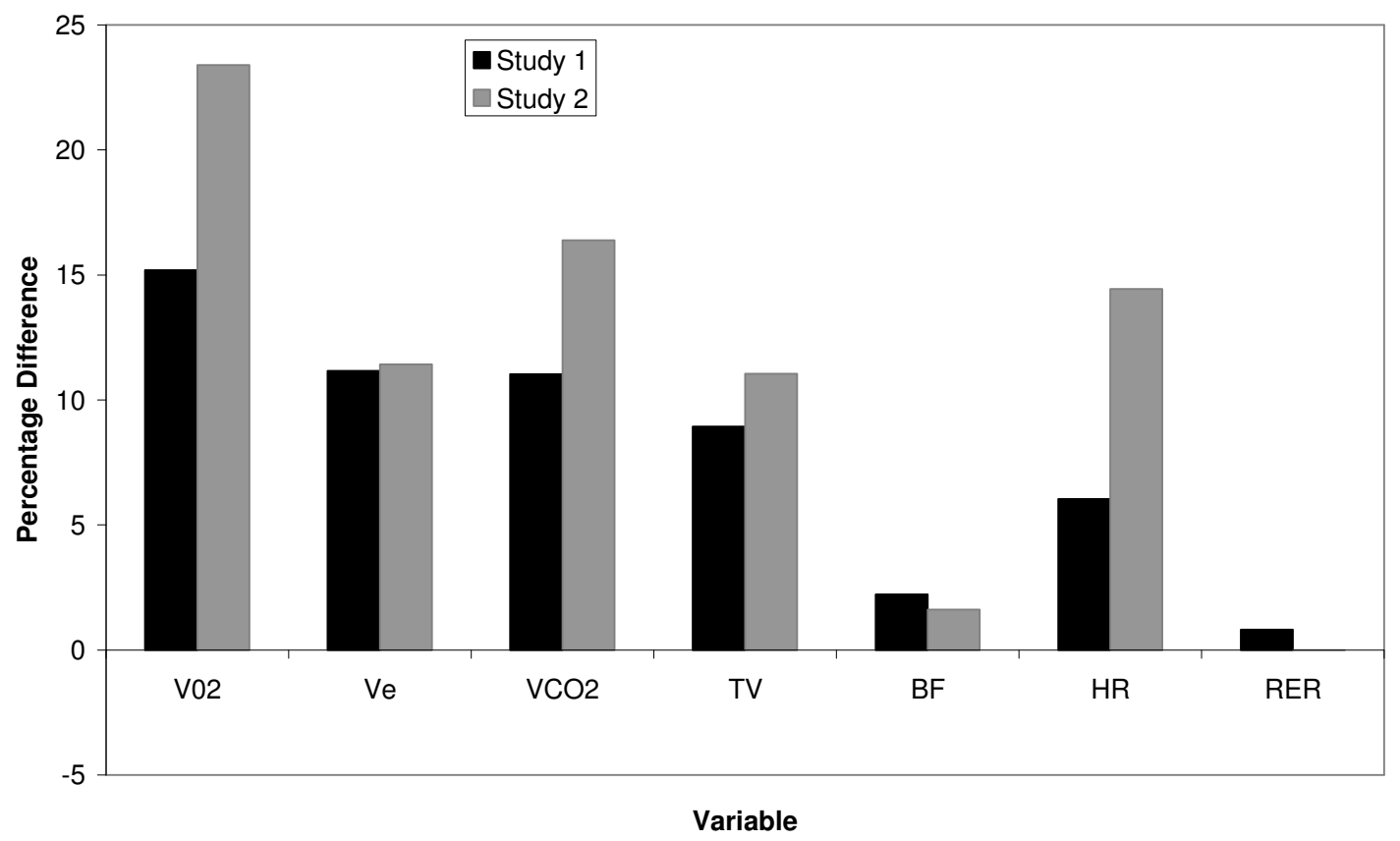

Fig 4 Overall percentage difference, calculated as increase above back-load condition, between back-loading and head-loading in cardiorespiratory variables across 10-25\% BM loads (Study 1) and $10-30 \%$ BM loads (study 2)

\section{Discussion}

The chosen walking speed in study $1,3.08 \pm 0.39 \mathrm{~km}^{-1} \mathrm{~h}^{-1}$, was similar to the speed employed in previous studies, in particular it is very close to the $\approx 3.0 \mathrm{~km}^{-1}$ defined as an optimal speed by Maloiy et al (1986). The speed chosen in study 2, $4.33 \pm 0.19 \mathrm{~km}^{-1}$, was significantly greater than that chosen in study 1 and presumably reflected the participants habituation to military marching speeds. As a consequence of this difference in locomotion speed, as well as factors such as fitness and load carriage history, no direct quantitative comparisons will be made 
in respect of cardiorespiratory parameters. Any comparisons between the two studies will be restricted to similarity or difference in pattern of response. The data for oxygen consumption associated with the back-loading condition in study 1 were, at least for the higher loads, consistent with previous studies, displaying a proportional increase in oxygen consumption with increasing load as reported by Taylor et al (1980). Mean percentage increases over the unloaded condition were $19.9 \%$ and $23.3 \%$ at loads of $20 \%$ and $25 \%$ BM respectively. At the lower loads, $10 \%$ and $15 \% \mathrm{BM}$, the mean percentage changes were $3.4 \%$ and 11.3\%. These were lower than might have been predicted but they were consistent with the data of Abe et al (2004) who reported a less than expected increase in energy expenditure for back-loading when relatively light loads were carried at slow speeds. In particular, they reported that loads of $6 \mathrm{~kg}, 9 \mathrm{~kg}$ and 12 $\mathrm{kg}$ carried at speeds of 3.0 and $3.6 \mathrm{~km}^{-1}$ were associated with significantly reduced energy cost of walking per unit distance when compared to unloaded walking. These speeds and load combinations are similar to those employed in study 1 where the average walking speed was $3.05 \mathrm{~km}^{-1}$ and the average loads at $10 \%$ and $15 \% \mathrm{BM}$ were $6.6 \mathrm{~kg}$ and $9.9 \mathrm{~kg}$ respectively. Abe et al (2004) argued that this phenomenon was a consequence of the interaction between increased 'rotative torque', presumably associated with the forward lean that accompanies back-loading (Lloyd and Cooke 2000b), and load on the lower limbs. The absence of this phenomenon for head-loading at first seems to provide some support for this idea. However, in the present study, the changes in oxygen consumption for the $10 \%$ and $15 \%$ BM loads associated with head-loading were $19.6 \%$ and $20.3 \%$ respectively. Given that forward lean is not present during head-loading, it would be reasonable to assume that the increased 'rotative torque' is absent. The data from study 2 , where the reduction in energy cost was absent 
(mean percentage changes of $8.9 \%, 21.0 \%$ and $37.5 \%$ for loads of $10 \%, 20 \%$ and $30 \% \mathrm{BM}$ respectively), provides further support for the data of Abe et al (2004) as the walking speed for these participants was much greater $\left(4.3 \pm 0.2 \mathrm{~km}^{-1}\right)$. More research is required to tease out the precise mechanisms for the energy saving phenomenon that seems to exist in certain conditions and, in particular, why it is both speed and load dependent.

In terms of other variables reported in the results which are either directly or indirectly related to oxygen consumption, such as minute ventilation, tidal volume, breathing frequency and heart rate, they are consistent with the patterns of response shown for oxygen consumption across the two studies. As expected, when oxygen consumption is greater then so is the minute ventilation and heart rate. The tendency for tidal volume to be greater during head loading could possibly be explained by postural differences and any possible chest restriction associated with wearing a backpack, especially since the tendency for a greater tidal volume was consistent with increasing loads. This is consistent with previous studies that have reported impaired abilities to increase tidal volume with increasing backpack load as a consequence of compromise to the respiratory muscles (Li et al, 2003; Lloyd and Cooke, 2000b). The increase in breathing frequency with loading is to be expected, given the increased energy demands and consistency of tidal volume for each loading condition, as it explains the associated increase in minute ventilation. Overall, the results for other cardiorespiratory variables support the pattern of response shown for oxygen consumption. This provides confidence in the interpretation of differences and similarities between the loading conditions and subject groups in terms of energy expenditure. 
Overall the data for oxygen consumption provide little support for the 'free ride hypothesis', with the head-loading being associated with significantly greater oxygen consumption than back-loading across the 10\%-25\% BM loads in study 1 and with a tendency for the same across the 10\%-30\% loads in study 2 . Figure 4 clearly shows that, on average, the percentage increase in oxygen consumption for the head-loading condition consistently lies above the line $y=x$ for both study 1 and study 2. If a 'free ride' for head-loading exists as a generalisable phenomena then the percentage increases for head-loading should lie below this line and indeed, should move further below the line with loads between 10 and $20 \%$. This was not the case for either of the groups studied. Considering study 1, it was anticipated that the EXP group would exhibit greater economy than the NON group when head-loading. The tendency for difference between the groups $(\mathrm{P}=0.069)$ and the lack of interaction between group and loading method $(\mathrm{P}=0.333)$ would suggest that, whilst the EXP group were generally more efficient load carriers than the NON group they were also more efficient whilst backloading than head-loading. Again this was a somewhat unexpected finding and stands in contrast to the seminal works in this area (Maloiy et al, 1986; Charteris et al, 1989a, Charteris et al, 1989b). One possible explanation for this is that the participants in these early studies were considerably more experienced headloaders than those used here. It is certainly the case that the six participants in the studies by Charteris et al (1989a, 1989b) were older and more experienced, age $33.7 \pm 9.4$ years and head-loading experience $22.5 \pm 8.9$ years, than the participants in the EXP group in the present study, who had at least ten years head-loading experience and were aged $22.5 \pm 2.1$. Maloiy et al (1986) provide no data in relation to age or experience, although the participants were 
characterised as experienced head-loaders. It would appear from these data that, although the participants in the present study had not been head-loaders for as long as those in the Charteris (1989a, b) studies, they had begun head-loading at approximately ten years of age, the same age as those in previous studies. It therefore seems unlikely that the differences in responses reported here can be explained by length of habituation. A more likely explanation lies in the variability of the data reported in the present study and the sample sizes of the earlier studies.

Examination of individual results in study 1 indicates that it would be possible to select a subset of women who did achieve remarkable levels of economy, in line with the previously reported data. Given the small sample sizes in most of the previous studies on head-loading this is not altogether unexpected but suggests that the 'free ride' hypothesis is not a generalisable finding, when tested with larger more representative samples of African women. Considering the oxygen consumption data across the $10-20 \%$ BM loads, five women demonstrated the 'free ride' phenomenon for head-loading (odds of selection 1:42504), with average increases above the unloaded condition of less than $0.5 \mathrm{ml} \mathrm{kg}^{-1}$, whilst seven demonstrated the same phenomenon for back-loading. Only two of the women feature in both subsets, one from each group. Remarkably, four of the five most economical head-loaders were women with no experience of head-load carriage. This would seem to indicate that structural changes to the spine associated with early and prolonged exposure to head loading are unlikely to provide explanations for such efficiency in individuals as previously speculated (Maloiy et al 1986). Conversely, six of the seven most economical back-loaders were from the EXP group. This was somewhat less unexpected as all of the 
women in the EXP group had experience of back-loading, as it is the traditional method for carrying young children, and were generally more experienced load carriers, regardless of method, than their counterparts in the NON group.

It has also been argued that body composition influences load carriage economy (Lyons et al. 2005) and that the explanation for the remarkable economy observed in some head-load carriers is a consequence of their low body fat (Jones et al 1987), with the extent of the 'free ride' being determined by the combination of fat and external load up to $140 \%$ of Fat Free Mass (FFM). Whilst this is helpful in untangling some of the issues relating to the 'free ride' hypothesis it does not provide support for the hypothesis as has been suggested. It would only provide an explanation if all extremely economical load carriers are relatively lean - in the present study the mean \pm sd BMI for the eleven women exhibiting some form of free ride for either carrying method was $24.0 \pm 5.1 \mathrm{~kg} \mathrm{~m}^{-2}$, implying that these women were, in general, not particularly lean. It might also be expected that if the size of the load relative to FFM is the determinant of economy then there would be a strong relationship between economy across different load carriage methods. However, in the present study it was apparent that economy in one method of carrying a load was not an indicator of economy in the other method $(\mathrm{r}=0.128, \mathrm{P}=$ 0.552). This lack of association between economy and load carriage method is an important finding. It suggests that cause and effect relationships between economy and load carriage are not likely to be explained by a common set of factors for different forms of load carriage in the same individuals, whether or not they are experienced in either or both forms of load carriage under investigation. This suggests that future research, and evaluations of previously completed studies in load carriage, should focus on the mechanisms responsible for the economy of individuals rather than expecting one or more mechanism to explain 
the observed variation within a particular method. This shift in focus, with a view to understanding how particular individuals carry loads more economically than others and why particular methods are more economical for some individuals than others, may provide a better understanding of the interactive effects of factors related to different forms of load carriage. There have been a number of explanations proposed for the greater economy of head-load carriage. Heglund et al. (1995) and Cavagna et al (2002) have argued, based on an analysis of the five participants in the original Maloiy et al (1986) study, that it is a consequence of improved energy exchange between gravitational potential energy and kinetic energy. Minetti et al. (2006), based on five experienced head-loaders carrying loads uphill but with no direct measurement of unloaded walking, suggested that balancing the loaded segment above the hip was an important mechanism. Abe et al. (2004) and Abe et al. (2008) reported an energy saving phenomenon at some load-speed interactions for back-loading and argued that this was a consequence of the interaction between 'rotative torque' and the burden on the lower limbs. In light of the data presented here it may be that such mechanisms are best examined on a case by case basis, attempting to account for individual difference rather than seeking general explanations. This may have implications for both military and recreational applications as it is likely to be the case that either the optimum load carriage system may be specific to an individual or that particular carrying methods require different techniques. Clearly individualisation of load carriage strategies may be impossible for most applications, although in some particularly sensitive cases it may be worthwhile. Nevertheless, an understanding of the factors that lead to improved economy in particular individuals, rather than pooled results, may well provide a useful way forward in the design and customisation of load carriage systems. 


\section{Conclusion}

The data presented here suggest that the 'free ride hypothesis' for head-loading is not a generalisable finding. The proportional increases in energy consumption are generally greater than the proportional increases in external load for both African and British women, regardless of head-loading experience. There was, however, some evidence of an energy saving effect when light loads were carried on the back at low speeds, further work is required to establish the mechanisms responsible for such a phenomenon. The data also revealed significant variation in load carrying economy, regardless of method, suggesting that there may not be a single set of factors determining load carriage economy but rather that different factors may align in individuals to influence economy. Further work is required to establish the nature of these factors and how they interact in individuals. Such information may well be useful when minimizing the energetic cost of load carriage is particularly important.

\section{Acknowledgements.}

This work was funded by:

The Carnegie Trust for Higher Education in Scotland

The School of Social and Health Sciences, University of Abertay Dundee

The Department of Sport Management, Cape Peninsula University of Technology 


\section{References}

Abe, D., Muraki, S. and Yasukouchi, A. (2008) Ergonomic effects of load carriage on energy cost of gradient walking. Applied Ergonomics 35: 329-335

Abe, D., Yanagawa, K. and Niihata, S. (2004). Effect of load carriage, load position, and walking speed on energy cost of walking. Applied Ergonomics 35: 329-335

Al-Khabbaz YS, Shimada T, Hasegawa M. (2008). The effect of backpack heaviness on trunklower extremity muscle activities and trunk posture. Gait Posture. 28(2):297-302.

Bastien, GJ. Willems, PA, Schepens, B. and Heglund NC. (2005a) Effect of load and speed on the energetic cost of human walking. European Journal of Applied Physiology 94: 76-83

Bastien, GJ, Schepens, P, Willems, PA and Heglund NC. (2005b) Energetics of load carrying in Nepalese porters. Science 308: 1755

Birrell SA and Hooper RH (2007). Initial subjective load carriage injury data collected with interviews and questionnaires. Military Medicine. 172(3):306-11.

Birrell, SA, Hooper, RH and Haslam, RA. (2007) The effect of military load carriage on ground reaction forces. Gait and Posture, 26: 611-614

Bobet J and Norman RW (1984). Effects of load placement on back muscle activity in load carriage. European Journal of Applied Physiology and Occupational Physiology. 53(1):71-5. Cavagna, G.A., P. A. Willems, P.A,. Legramandi M. A and Heglund N. C. (2002) Pendular energy transduction within the step in human walking Journal of Experimental Biology 205: 3413-3422 Charteris, J., Nottrodt, J.W. and Scott, P.A. (1989a) The 'free ride' hypothesis: a second look at the efficiency of African women headload carriers. South African Journal of Science 85:68-71 Charteris, J., Scott, P.A. and Nottrodt, J.W. (1989b) Metabolic and kinematic responses of African women headload carriers under controlled conditions of load and speed. Ergonomics 32:15391550

Chow, HK, Kwok, M, Au-Yanf, A, Holmes, A, Cheng, J, Yao, F and Wong, MS. The effect of backpack load on the gait of normal adolescent girls. Ergonomics 6: 642-656

Datta, S.R. and Ramanathan, N.L. (1971) "Ergonomic comparison of seven modes of carrying loads on the horizontal plane." Ergonomics 14(2):269-278

Datta SR, Chatterjee BB, Roy BN (1973). The relationship between energy expenditure and pulse rates with body weight and the load carried during load carrying on the level. Ergonomics.

16(4):507-13.

Heglund, N.C., Willems, P.A., Penta, M. and Cavagna, G.A. (1995) Energy saving gait mechanics with head-supported loads. Nature 375: 52-54

Holewijn M (1990). Physiological strain due to load carrying. European Journal of Applied Physiology and Occupational Physiology. 61(3-4):237-45

Jones, C.D.R., Jarjou, M.S., Whitbread, R.G. and Jequier, E. (1987) Fatness and the energy cost of carrying loads in African women The Lancet 12: 1331-1332

Kirk J and Schneider DA (1992). Physiological and perceptual responses to load-carrying in female subjects using internal and external frame backpacks. Ergonomics. 35(4):445-55. 
LaFiandra, M, Wagenaar, RC, Holt, KG and Obusek, JP (2003). How do load carriage and walking speed influence trunk coordination and stride parameters? Journal of Biomechanics 36: $87-95$

Legg, S.J. and Mahanty, A. (1985) Comparison of five modes of carrying a load close to the trunk. Ergonomics 28: 1653-1660

Li, J.X., Hong' Y. and Robinson, P.D. (2003) The effect of load carriage on movement kinematics and respiratory parameters in children during walking. European Journal of Applied Physiology and Occupational Physiology. 90: 35-43

Lloyd, R. and Cooke C.B. (2000a) "The oxygen consumption associated with unloaded walking and load carriage using two different backpack designs." European Journal of Applied Physiology and Occupational Physiology. 81 (6) pp 486-492

Lloyd, R. and Cooke, C.B. (2000b) Relationships between physiological and postural adjustments to load carriage for rucksack designs. Journal of Sports Science 18: 25-26

Lyons, J., Allsopp, A. and Bilzon, J. (2005) Influences of body composition upon the relative metabolic and cardiovascular demands of load carriage. Occupational Medicine 55: 380-384 Mackie, HW and Legg, SJ (2008). Postural and subjective responses to realistic schoolbag carriage. Ergonomics 51(2) 217-231

Maloiy, G.M., Heglund, N.C., Prager, L.M., Cavagna, G.A. and Taylor, C.R. (1986) Energetic costs of carrying loads: have African women discovered an economic way? Nature 319 668-669 Malville, N.J., Burns, W.C., LimHa and Basnyat, R. (2001) Commercial porters of Eastern Nepal: health status, physical work capacity and energy expenditure. American Journal of Human Biology 13: 44-56

Minetti, A.E., Formenti, F. and Ardigo, L.P. (2006) Himalayan porter's specialization: metabolic power, economy, efficiency and skill. Proceedings of the Royal Society B. 273: 2791-2797 Myles WS and Saunders PL (1979). The physiological cost of carrying light and heavy loads. European Journal of Applied Physiology and Occupational Physiology. 42(2):125-31

Nag PK, Sen RN, and Ray US (1979). Cardio-respiratory performance of porters carrying loads on a treadmill. Ergonomics. 22(8):897-907

Quesada PM, Mengelkoch LJ, Hale RC, Simon SR (2000). Biomechanical and metabolic effects of varying backpack loading on simulated marching. Ergonomics. 43(3):293-309

Rorke, S.L. (1990) Selected factors influencing the "optimum" backpack load for hiking. South African Journal of Research in Sport Physical Education and Recreation 13: 31-45

Sharpe, SR, Holt, KG, Saltzman, E, and Wagenaar, RC (2008). Effects of hip belt on transverse plane trunk coordination and stability during load carriage. Journal of Biomechanics 41: 968-976 Soule, R.G. and Goldman, R.F. (1969) Energy costs of loads carried on the head, hands or feet. Journal of Applied Physiology 27 687-690

Stuempfle, KJ, Drury, DG and Wilson, AL. (2004). Effect of load position on physiological and pereceptual responses during load carriage with an internal frame backpack. Ergonomics 47(7): 784-789

Taylor, C.R., Heglund, N.C., McMahon, T.A. and Looney, T.R. (1980) Energetic cost of generating muscular force during running. Journal of Experimental Biology 86 9-18 